\title{
Comparative Public Administration
}

\author{
Dr S. B. M. Marume ${ }^{1}$, R. R. Jubenkanda ${ }^{2}$, C. W. Namusi ${ }^{3}$ \\ ${ }^{1}$ BA, Hons BA, MA. MAdmin, MSoc Sc, $\mathrm{PhD}$ \\ ${ }^{2}$ BSc, MSc. Econ, MSc, DPhil (Candidate) \\ ${ }^{3}$ BAdmin (Hons), MPA, DPhil (Candidate)
}

\begin{abstract}
It is recognised that comparative public administration stands for cross-cultural and cross-national public administration whose two basic motivational concerns include: (a) theory-building, (b) administrative problems and challenges of the developing countries evidently of Africa and the Middle East, Asia and Latin America.
\end{abstract}

Keywords: comparative public administration; cross cultural and cross national character; developing countries; developed countries

\section{Preface to the article}

This subject of this article is designated as comparative public administration. A number of scholars do not regard it as a distinct sub-field but rather be regarded as a method and prefer to regard it as a comparative method of studying public administration. This time of thinking has led to the empirical observation that vigilant public administration scientists and researchers are amongst the quick ones to admit that comparative public administration has been the first major visible development in the past world-war evolution of public administration. It aims at the development of much more systematic and scientific public administration by constructing and enhancing theory in public administration. In the words of Lyton Coldwell, its objective has been to hasten the emergence of a universally reliable and valid system of knowledge regarding administrative behaviourist in an endeavour to contribute to a genuine and generic social discipline of public administration.

\section{Synopsis}

For a better view of the present discussion, we may be necessary to demonstrate that comparative public administration focuses on the method of the study of public administration which is concerned with making rigorous systematic cross-cultural and cross-national comprises of the structures, institutions, dynamic, actions and processes involved in the activity of running public affairs. As rightly observed by Professor Nicholas Henry, comparative public administration is different from traditional at American public administration in two respects, namely, (a) public administration is ,cultural-bound (ethnocentric), while comparative public administration is ,cross cultural in its orientation and thrust. (b) Public administration is ,practitioner-oriented ee and involves the real world, whereas comparative public administration attempts to the ,theorybuilding ${ }^{\text {ee }}$ and seeks knowledge for the sake of knowledge. It is acknowledged that Professor Fredrick W. Riggs, who in the foremost model-builder in comparative public administration, uses three analytical tool, to explain his administrative theories; namely, (a) ecological approach (ecological perspectives); (b) structural-functional approach; and (c) idea models (moral-building). He has developed his theories to the extent that his theories have attracted wider recognition and are developed to be called: (i) agrarianindustrial model; (ii) fused-prismatic-diffracted model; and (iii) prismatic-sala model.

\section{Introduction}

Comparative public administration has been the first visible major development in the past world-war evolution of public administration. It aims at the development of a more systematic and scientific public administration by constructing and enhancing theory in public administration. In the words of Professor Lynton Coldwell, its objective has been hasten the emergence of a universally reliable and valid system of knowledge regarding administrative behaviour in order to contribute to a genuine and generic discipline of public administration. Two points need mentioning: (a) leading scholars and (b) the nature and scope of comparative public administration as follows:

Firstly, the following are leading scholars in comparative public administration:

\begin{tabular}{|lll|}
\hline - Lynton Coldwell & •Ferrel Heady & •N. Raphaeli \\
- R.H Jackson & -Jong S. Jun & -S.B.M Marume \\
- N.Henry & •L.D White & -R.A Dahl \\
- D. Waldo & •F.WRiggs & •R.KMerton \\
- R.T Golembiowski & -Talcott Parsons & •C.T Goodsell \\
- G.ECaiden & •Naomi Caiden & -RoscoeMartin \\
\hline
\end{tabular}

Secondly comparative public administration stands for crosscultural and cross-national public administration. It has two basis motivational concerns; namely, a) theory-building, and b) administrative problems and challenges of the developing countries evidently of Africa and the Middle East, Asia and Latin America. Professor Ferrel Heady describes the period of the late 1960s as the heyday of the comparative public administration moment.

\section{Definitions}

There are five definitions from five selected authors:

\section{Nimrod Raphaeli:}

"Comparative public administrative is a study of public administration on a comparative basis." He traced the origin 


\section{International Journal of Science and Research (IJSR) \\ ISSN (Online): 2319-7064}

Index Copernicus Value (2013): 6.14 | Impact Factor (2014): 5.611

of comparative public administration to the 1952 Conference on Administration held at Princeton University in USA. He said, "comparative public administration is a new corner to the community of academic instruction and research."

\section{Robert H. Jackson:}

"Comparative public administration is that facet of the study of public administration which is concerned with making rigorous cross-cultural comparisons of the structures and processes involved in the activity of administering public affairs.

\section{Comparative Administrative Group (CAG):}

"Comparative public administration is a theory of public administration applied to the diverse cultures and national settings and the body of factual data by which it can be examined and tested."

\section{Jong S. Jun:}

"Comparative public administration has been predominantly cross-cultural or cross-national in orientation."

\section{S.B.M Marume (1976):}

Comparative public administration is that method of the study of public administration which is concerned with making rigorous systematic cross-cultural comparisons of the structures, institutions actions and processes involved in the activity of running the public affairs.

As rightly observed by Nicholas Henry, comparative public administration is different from traditional or American public administration in two respects:

(a) Public administration is 'çulture-bound' (ethnocentric) while comparative public administration is 'crosscultural' in its orientation and thrust. In 1936, L.D. White observed that a principle of administration is as useful a guide to action in the public administration of Russia as of Great Britain, of Iraq as of United States. But later Robert Dahl (in 1947) and Dwight Waldo (in 1948) pointed out that cultural factors could make public administration on one part of the globe quite a different animal from public administration on the other part.

(b) Public administration is ,practitioner-oriented ${ }^{\text {ee }}$ and involves the ,real worlde, whereas comparative public administration attempts to the ,theory-building ${ }^{e e}$ and „seeks knowledge for the sake of knowledge." In brief, the comparative public administration has a purely scholarly thrust, as opposed to professional.

While highlighting the significance of comparative public administration, Professor Fred W. Riggs asserted that American public administration should be viewed as a subfield because public administration is global in scope. To quote Fred Riggs: "The new paradigm for public administration must be comparative i.e., global, since the solution of the problem to which it addresses itself will require increasing communication between scholars and practitioners in all countries. The American dimension will be viewed as a sub-field or a practical aspect of the broader subject."

\section{Formulation of Comparative Administrative Group (CAG)}

The most important single contribution to the growth of comparative public administration came from the Comparative Administration Group (CAG), established in 1960 as a Committee of the American Society for Public Administration (ASPA, founded in 1939). The eminent scholars associated with the CAG were Fred Riggs, Alfred Diamant, Ferrel Heady, Dwight Waldo, Wallaca Sayre, Martin Landau, William Saffin, John Montgomary, Ralph Braibanti, Bertram Gross and others.

However, Professor Fred Riggs is the major exponent of comparative approach to public administration. $\mathrm{He}$ is considered as the father of comparative public administration. He was the chairman of CAG for one decade (1960-1970). He was succeeded by Richard Gable.

With regard to the composition and basis thrust of CAG Professor Fred Riggs observed, "The CAG consisted largely of scholars who had served on technical cooperation missions in many parts of the third world, under conditions which showed the accepted administrative doctrines of American practice to be severely limited in their applicability to different cultural situations. It was natural, consequently, that the members of CAG should be keenly interested in the revision of these doctrines on the basis of an improved understanding of the forces affecting administrative behaviour in these countries."

The comparative public administration got real impetus in 1962 when the CAG received the financial support from the Ford Foundation. The CAG developed a programme with three objectives:

- to encourage research in comparative public administration;

- to encourage teaching of comparative public administration; and

- to contribute to more effective public policy formulation in the field of development administration.

\section{Purposes of the Article}

According to Professor Ferrel Heady, the comparative public administration addresses five ,motivating concerns ${ }^{\text {ee }}$ as an intellectual enterprise. These are:

(a) The search for theory;

(b) The urge for practical application;

(c) The incidental contribution of the broader field of comparative politics;

(d) The interest of researchers trained in the tradition of administrative law; and

(e) The comparative analysis of ongoing problems of public administration.

Professor Fred Riggs stated that the purpose of comparative public administration have a combination of empirical and normative concerns which are reflected in the literature of comparative public administrative analysis. According to him, the comparative public administration has the following four purposes:

- "To learn the distinctive features of a particular system or cluster of systems.

- To explain the factors responsible for cross-national and cross-cultural differences in bureaucratic behaviour. 


\section{International Journal of Science and Research (IJSR) \\ ISSN (Online): 2319-7064}

Index Copernicus Value (2013): 6.14 | Impact Factor (2014): 5.611

- To examine the cause for the success or failures of particular administrative features in particular ecological settings.

- To understand strategies of administrative reform."

According to Robert T. Golembiewski, "comparative public administration emphasises that (a) organisations must be viewed as embedded in specific cultures and political settings, (b) the principles of public administration are seriously inadequate, (c) both the study and practice of administration are pervasively value-loaded, and (d) any proper discipline must have complementary pure and applied aspects."

\section{Sources/Causes}

The factors that contributed to the raise and growth of comparative public administration are:

1) The revisionist movement in comparative politics due to dissatisfaction with the traditional approaches.

2) The dissatisfaction with traditional public administration which was culture-bound.

3) Intellectually oriented catalysts, that is, to develop universally relevant theoretical models.

4) Exposure of American scholars and administrators to the new features of the administrative systems of developing countries during the World War II period.

5) The emergence of newly independent Third World countries which attempted to achieve rapid socioeconomic development, creating opportunities for scientific investigation.

6) Policy oriented catalysts, that is, to develop the practical knowledge to make policy-formulation and policyexecution more effective.

7) The scientific, technological and theoretical development which have influenced the forms of administrative structures.

8) The extension of American foreign aid programme (both political and economic) to newly emerged developing countries.

9) The rise of behavioural approach in public administration as a reaction to the classical structural approach.

\section{Trends}

Professor F. W. Riggs noticed three trends in the comparative study of public administration.

(a) A shift from normative studies (which deals with what ought to be) to empirical studies (which deals with what is).

(b) A shift from ideographic studies (one nation studies/individualistic) to nomothetic studies (universal studies).

(c) A shift from non-ecological studies (which examines administrative phenomena as a isolated activity) to ecological studies (which examines administrative phenomena in relation to its external environment).

Thus, comparative public administration, according to Fred Riggs, is:

i. Empirical, that is, factual and scientific.

ii. Nomothetic, that is, abstracted and generalizable.

iii. Ecological, that is, systematic and non-parochial

\section{Conceptual Approaches}

Professor Ferrel Heady identified four conceptual approaches in comparative public administration.

- Modified Traditional

- Development Oriented

- General System Model Building

- Middle-range Theory Formulation

- Departing somewhat form from Headyes four-fold classification, Henderson gave a three-fold classification of conceptual approach in the comparative public administration, viz.

- Bureaucratic System Approach

- The Input-Output System Approach

- The Component Approach

- The following are the various approaches/models in the study of comparative public administration.

(i) The Bureaucratic System Approach adopted by Alfred Diamant, Robert Presthus, Ferrel Heady, Micheal Crozier, Morroe Berger, and so on.

(ii) The General System Approach adopted by F.W Riggs in his "Fused-prismatic-diffracted typology" and John T. Dorsey in is "information energy model."

(iii) The Development Administration Approach adopted by Riggs, Wiedner, and others emphasising directed socioeconomic change.

(iv) The Decision-making Approach advocated by Martin Landau to increase the decision-making capacity of developing countries ${ }^{\text {ee }}$ administrative system to avoid "muddling through" technique.

(v) Anthony Downs Model which differentiated five categories of bureaucrats, namely, climbers, conservers, zealots, advocates and statesmen.

(vi) Structural-Functional Model advocated by Talcott Parsons, involving the concept of ,Social System ${ }^{\text {ee }}$ as a given and the society in terms of its structures and functions.

(vii) Other models developed by Paul Meyer, F.M. Marx, and Brain Chapman, emphasising on the comparative study administrative organisation and Civil Service System in the western developed countries.

Of all the above approaches in the study of comparative public administration, the Bureaucratic System Approach (Bureaucratic model of Max Weber) is the most influential and most useful. To put it in the words of Ramesh K. Arora, "Max Weber"s ,idea type" construct of bureaucracy has been the single-most dominant conceptual framework in the study of comparative administration". In fact in 1964 itself, Dwight Waldo found the bureaucratic model useful, stimulating, and provocative. According to him, the model ,is set in a large framework, that spans history and cultures and related bureaucracy to important societal variable, yet it focuses attention upon the chief structural and functional characteristics of bureaucracy". He considered the model as a ,paradigm ${ }^{\text {ee }}$ of public administration.

\section{Decline}

The beginning of the 1970s saw the decline of the comparative public administration. In 1971, the Ford 


\section{International Journal of Science and Research (IJSR) \\ ISSN (Online): 2319-7064}

Index Copernicus Value (2013): 6.14 | Impact Factor (2014): 5.611

Foundation terminated its finical support to the CAG. In 1973, the CAG itself was disbanded and merged with the International Committed of the American Society for Public Administration to form a new Section on International and Comparative Administration (SICA). Its major journal The Journal of Comparative Administration ceased to publish from 1974, after five years of existence. Its legacies were absorbed into the larger field of political science and public administration. On failure of comparative public administration, Robert T. Golembiewski said, "Public administration should take full notice of the fact that comparative administrations failure rests substantially on a self-imposed failure experience. It set an unattainable goal, that is, in its early and persisting choice to seek a comprehensive theory or model in terms of which to define itself ". Similarly, Peter Savage, who served as the editor of The Journal of Comparative Administration (published for a five-year period from 1969 to 1974), observed, "Comparative administration started with no paradigm of its own and developed none."

\section{Significance}

Nevertheless, the CAG has made a significant contribution to the field of public administration. Ramesh.K. Arora identified the four elements of its contribution, viz.,

1) It has widened the horizons of public administration.

2) It has opened the doors of the discipline to all kinds of social scientists.

3) It has made the scope of the field more systematic by studying different administrative systems in their ecological settings.

4) It has stimulated interest on the part of its members in the problems of developing administration.

According to T. N Chaturvedi, the various contributions of comparative study in public administration are:

(i) It has helped to eliminate the narrowness of ,provincialism ${ }^{\text {ee }}$ and ,regionalismee.

(ii) It has broadened the field of social science research, which was earlier confined to cultural limitations.

(iii) It has led to a greater scientific outlook in theory construction.

(iv) It has encouraged O.P. Dwivedi the process of broadening the field of social analysis.

(v) It has played am important role in making the subject of public administration broader, deeper, and useful.

(vi) It has brought politics and public administration closer to each other.

\section{Revival Movement}

In early 1980 s, a number of scholars started a movement for revival of comparative public administration. They made efforts to arrest the downward trend of the field and to give a fresh life to it. These scholars included Ferrel Heady, Charles T. Goodsell, Jung S. Jun, Milton Esman, G.E Caiden, Naomi Caiden, and others.

Ferrel Heady, who spearheaded the resurrection attempts, emphasized: "At this juncture, what comparative public administration needs is not prolonged post mortem of the past contributions but vigorous pursuit of attractive new opportunities.
Charles T. Goodsell in his article entitled "The New Comparative Administration: A Proposal “ (1981) recommended that the scope of comparative public administrative should be extended to cover comparisons at supra-national and sub-national levels of analysis. To him, it should embrace all studies of administrative phenomena where the comparative method in some guise is explicitly employed.

According to Jong S. Jun, the comparative public administration did not deal with comparison of methods and strategies of organisation change and organisational development in a cross-cultural context. Hence, he suggested that the revival in comparative studies must incorporate these aspects.

\section{CPA and IPA}

In 1973, the SICA was incorporated as the first section of the ASPA to promote the study and practice of comparative public administration (CAP) and international. Unlike the CPA (which is concerned with the study patterns of public administration in different nations), the IPA is concerned with the study of administrative operations of international agencies. However, both the CAP and IPA were unable to develop an appropriate framework or paradigm for analysis.

Ferrel Heady suggested for the convergence of these two sub-field or public administration for their mutual benefit. According to him, both CPA and IPA are similar because both avoid concentration on the administrative system of any single nation and both have many attributes. He said that the agenda for the future of these two sub-fields is to combine the forces more effectively by a closer familiarity on the part of each group with the work of the other, leading to a gradual convergence. He viewed that SICA has a catalyst role in this convergence process. He suggested that SICA should make bringing these two sub-fields together a major programme objective.

\section{Future Prospects}

About the future of comparative public administration, Ferrel Heady said that the "comparative perspective will become more prominent, enriching general public administration by widening the horizon of interest in such a way that understanding of one's own motivational system of administration will be enhance by placing it in a crossculture setting.

In the present era of globalisation and liberalisation, the interaction between the nations of the world has increased. In this context, the new thrust areas for an analysis of comparative public administration can include the following:

1) Human rights enforcement.

2) Disinvestment of public sector enterprises.

3) International interdependency of bureaucracies.

4) Study on citizen charter.

5) Role of people in promoting or resisting administrative reforms.

6) Debureaucratisation.

7) Role of private sector.

8) Role of voluntary agencies/non-governmental organisations. 


\section{International Journal of Science and Research (IJSR) \\ ISSN (Online): 2319-7064 \\ Index Copernicus Value (2013): 6.14 | Impact Factor (2014): 5.611}

9) Role of self-help groups.

10) Role of community-based organisation.

\section{Comparative models of Professor F.W. Riggs}

Fred F.W Riggs Riggs is the foremost model-builder in comparative public administration. Ferrel Heady says that Riggs' book Administration in Developing Countries: The Theory of Prismatic Society (1964) continues to be probably the most notable single contribution in comparative public administration.

Professor Riggs employed three analytical tools to explain his administrative theories. These are

1)ecological approach (ecological perspectives);

2) structural-functional approach; and

3)idea models (model-building).

Ecological approach studies the dynamics of interaction between administrative system and its environment consisting of political, social, cultural and economic dimensions. It assumes that administrative system is one of the various sub-systems of society and is influenced and in turn, also influences them.

The ecological approach in the study of public administration was initiated by J.M. Gaus (1947), Robert A. Dahl (1947), Roscoe Martin (1952), and (1961) is the foremost exponent of the ecological approach in public administration.

F.W Riggs in his book entitled The Ecology of Public Administration (1961) explored the dynamics of interaction between public administration and its external environment.
He adopted the structural -functional approach in explaining the administrative systems from ecological perspective. The adoption of this approach in the field of public administration was first suggested in 1955 by Dwight Waldo. apart from Riggs, the Structural-Functional Approach was adopted by Talcott Parsons, Robert Merton, Marion Levy, Gabriel Almond, David Apter, and others.

According to the Structural-Functional Approach, every society has various structures which perform specific functions. Riggs identified five functions which are performed in each society. They are political, economic, social, symbolic and communicational functions. He stated that, same set of functional requisite apply to an administrative sub-system.

Based on the structural-functional approach, F.W. Riggs has constructed two 'ideal models' (theoretical models) to explain the administrative system in a comparative context These are (i) agraria-industria model; and (ii) fusedprismatic-diffracted model.

\section{Agraria-industria model of analysis}

Riggs developed the agraria-industria topology in 1956. In this model, he distinguished between two types of societiessocieties dominated by agricultural institutions and societies dominated by industrial institutions. These two polar types represented the Imperial China and contemporary USA. According to him, all societies move from agraria stage to industrial stage. This is an unidirectional movement. he identifies the structural features of the agrarian and industrial societies. These are mentioned below in Table 1.1

Table 1.1: Features of agraria and industria

1. Ascriptive values
2. Particularistic norms
3. Diffuse patterns
4. Stable local groups and limited spatial mobility
5. Simple and stable occupational differentiation
6. Deferential stratification system

1. Ascriptive value

3. Diffuse pattern
1. Achievement values
2. Universalistic norms
3. Specific patterns
4. High degree of social and spatial mobility
5. Well-developed occupational system
6. Egalitarian class system
7. Prevalence of associations which are functionally specific and non-ascriptive

In the following year (1957), Riggs postulated an intermediate model called 'transitia' which bears the features of both agraira and industria and thus represents a transitional society.

Soon after its formulation, the agraria-industria model met with criticism as it had the following limitations:

1) It does not help in examining the transitional societies. The intermediate model (transitia) is less developed than the two polar types.

2) It does not provide sufficient mechanism to study mixedtype societies. Critics argue that the modern industrial societies will always have some agraria features.

3) It assumes a unidirectional movement from an agraria stage to an industria stage.

4) Its major stress is on the environment of the administrative system but not on the administrative system per se.

5) It is too general and abstract with little resemblance to concrete reality.

Consequently, Riggs abandoned this topology of agriaratransitia-industria and formulated another improvised fusedprismatic-diffracted model.

\section{Fused-prismatic-diffracted model of analysis}

The fused-prismatic-diffracted (refracted) model represents the underdevelopment, developing and developed societies respectively. To quote Riggs, "Traditional agricultural and folk societies approximate the fused model, and modern industrial societies (industria) approach the refracted model. The former is 'functionally diffuse', the latter 'functionally specific'. Intermediate between these polar extremes is the prismatic model, so called because of the prism through which fused light passes to become refracted. "Thus, a fused society is one in which a structure performs a limited number of functions. In between these two polar types, comes the category of prismatic society. It is a transitional society and hence combine the features of both. It refers to a society that is semi-differentiated, standing midway between an undifferentiated fused society and a highly differentiated diffracted society. This is illustrated below: 
International Journal of Science and Research (IJSR)

ISSN (Online): 2319-7064

Index Copernicus Value (2013): 6.14 | Impact Factor (2014): 5.611

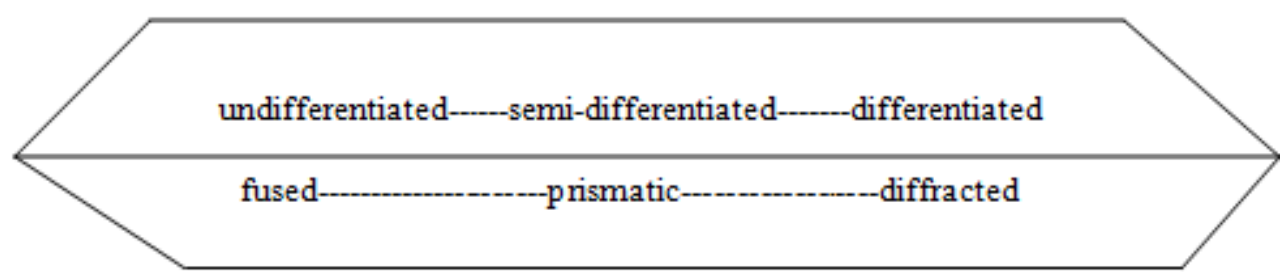

According to Riggs, these three types of societies have the following attributes.

Table 1.2: Attributes of fused, prismatic and diffracted societies Fused Prismatic Diffracted

\begin{tabular}{|c|c|c|}
\hline Ascription & Attainment & Achievement \\
Particularism & Selectivism & Universalism \\
Functional diffusion & Poly-functionalism & Functional specificity \\
\hline
\end{tabular}

In describing these attributes (characteristics) of his model societies, Riggs made used of the pattern variables of Talcott Parsons. He also developed intermediate categories of pattern variables (in the case of prismatic society).

\section{Prismatic-sala model of analysis}

Riggs was mainly interested in analysing the interaction and the administrative system and its environment in prismatic societies. For this purpose, he constructed the 'prismatic-sala' model in which 'prismatic' represents the prismatic society (transitional or developing society) and 'sala' represents the administrative sub-system of a prismatic society. He identified the following three features of prismatic-sala model-.

Heterogeneity A prismatic society has a high degree of heterogeneity, that is, the simultaneous presence, side by side, of quite different kinds of systems, practices and viewpoints. The sala is also heterogeneous as it combines the elements of 'chamber' of a fused society and 'bureau' of a diffracted society.

Formalism A prismatic society has a high degree of formulism, that is, a degree of discrepancy or incongruence between the formally prescribed and the effectively practiced, between norms and realities. In short, it refers to the gap between theory and practice.

Overlapping A prismatic society has overlapping phenomena, that is, the extent to which formally differentiated structures of a diffracted society co-exist with undifferentiated structures of a fused society; overlapping in sala refers to what is described as administrative behaviour but which is actually determined by non-administrative criteria, that is, by political, economic, social, religious or other factors. It has five different aspects.

Nepotism Riggs says that 'sala' is characterised by nepotism in recruitment.

Polynormativism This means co-existence of modern existence and traditional 'norms' leading to lack of consensus on norms of behaviuor.

Polycommunalism This means simultaneous existence of various ethnic and religious groups in a hostile interaction with each other. Riggs calls them 'clects', that is, club sect.
Bazaar-canteen model Riggs calls the economic subsystem of a prismatic society as the 'bazaar-canteen model'. This combines the elements of market economy of diffracted society and traditional economy of fused society. Such a situation produces a kind of 'price indeterminacy'. This implies that the prices of goods and services keep fluctuating.

Authority versus Control The authority structure of a prismatic society is highly centralised and concentrated while the control system is highly localised and dispersed. Hence, a prismatic society has an 'unbalance polity' in which administrators dominate the politico-administrative system.

\section{Change in a prismatic society}

According to Riggs, the pace of development in any society is related mainly to the sources of change. The western societies were able to adjust their effective behaviour gradually to the evolving behaviour since they had relatively long time span for their development. Consequently, these societies experience less heterogeneity, formalism and overlapping than the contemporary developing (transitional) societies.

In a prismatic society, the pressure for change is external as well as internal. When it is external, it is called 'exo-genous' change and when internal, it is called 'endo-genous' change. Further, when the change is caused by both external and internal pressures, it is called 'equi-genetic change'.

Riggs stated that greater heterogeneity, formalism and overlapping are likely to exist in an 'exo-prismatic' society (the society where the pressure for change is primarily external) than in an 'endo-prismatic' society (the society where the pressure for change is primarily internal). The reason is that in an 'endo-prismatic' society change, effective behaviour precedes the establishment of new formal institutions, while in an 'exo-genetic' change the sequence is reversed. The prismatic (transitional) societies face the problems of greater heterogeneity, formalism and overlapping in their bid to absorb the externally induced change in the shortest possible time.

\section{Revised Prismatic Theory}

In his book Prismatic Society Revisited (1973), Riggs revised his prismatic theory. In his new formulation he replaced the 'one dimensional approach' (i.e., differentiation) with 'two dimensional approach' (i.e., into differentiation and integration). He further sub-divided the two basic diffracted and prismatic societal model into finer types on the basis of degree of integration. Thus, he reconceptualised diffracted societies as 'eo-diffracted'. 'ortho-diffracted' and 'neo-diffracted' and prismatic societies as 'eo-prismatic', ortho-prismatic and 'neo-prismatic'. 


\section{International Journal of Science and Research (IJSR) \\ ISSN (Online): 2319-7064}

Index Copernicus Value (2013): 6.14 | Impact Factor (2014): 5.611

\section{References}

[1] S.J. Colin Campbell and B. Guy Peters (eds) Organising Governance, Governing Organisations: Pittsburg: University of Pittsburg Press, 1988.

[2] James C. Charlesworth (ed): Theory and practice of Public Administration: scope, objectives and methods: Philadelphia: American Academy of Political and Social Sciences, 1968.

[3] E.N Gladden: A History of Public Administration: London: Frank Cass and Company, 1972.

[4] Ferrel Heady: Public Administration: A Comparative Perspective: $3^{\text {rd }}$ edition: Englewood Cliffs: New Jersey: Prentice-Hall, 1984.

[5] Ferrel Heady: "Comparative Public Administration: Concerns and Priorities," in Papers in Comparative Public Administration, (eds.), Ferrel Heady and Sybil Stokes: Ann Arber: MI: Institute of Public Administration, 1962.

[6] James L. Perry (ed): Handbook of Public Administration: San Francisco: Jossey-Bosso, Inc, 1989.

[7] Herbert A. Simon; Donald W. Smithburg and Victor A. Thompson: Public Administration $7^{\text {th }}$ edition: New York: Knopf, 1971.

[8] Dwight Waldo: The study of Public Administration: New York; Random House, 1955.

[9] Leonard D White, "The Meaning of Principles of Public Administration," in The Frontiers of Public Administration, (eds), John M. Gaus, Leonard D White, and Marshall E. Dimock: Chicago: University of Chicago Press, 1936.

[10] Leonard D. White: Introduction to the Study of Public Administration: New York: Macmillan, 1955.

\section{Author Profile}

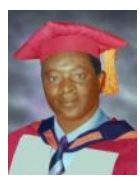

Samson Brown Muchineripi Marume: born on 15 July 1943; a former senior civil servant for 37 years and deputy permanent secretary; ten years as a large commercial former; well travelled domestically, regionally [SADC countries and Africaes Kenya, Ethiopia, Sudan, Libya, Uganda]; and internationally [Washington, New York and California in USA; Dublin and Cork in Ireland; Netherlands, France, former Yugoslavia Belgrade; Rome and Turin in Italy; Cyprus - Nicosia; Athens - Greece; Beijing - China; Singapore; Hong Kong; Japan; and UK]; six years as management consultant and part - time lecturer and $\mathrm{PhD} / \mathrm{DPhil}$ thesis supervisor, internal and external examiner; researcher and writer and currently senior lecturer and acting chairperson of Department of Public Administration in Faculty of Commerce and Law of Zimbabwe Open University; is a graduate BA, special Hons BA, MA [Public Administration] [Unisa, South Africa], MAdmin magna cum laude in transport economics, MSoc Sc cum laude in international politics, $\mathrm{PhD}$ summa cum laude in public administration [CUAS, California, United States of America].

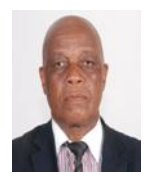

Roy Robson Jubenkanda: 2008, DPhil (Currently pursuing DPhil pursuing DPhil studies with (ZOU); 2000, MSc in Strategic Management - University of Derby, U. K; MSc. Econ. In international Economics, Banking and Finance- University of Wales, Cardiff College of Business Studies, U.K.; 1983, BSc (Hons) Degree in Economics - University of Zimbabwe, Zimbabwe; 1976 Business Studies Diploma - Solusi University, Zimbabwe; 2005, Certificate in Distance Education Practitioner (UNISA); 2011, Certificate in
Higher Education Management in Southern Africa (University of the Witwatersrand) Johannesburg, South Africa.

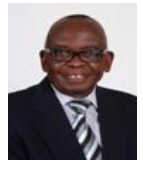

Cornelius Wonder Namusi: current studies: DPhil (candidate) in Public Administration; 1991, Master of Public Administration (UZ); 1982, Bachelor of Administration Honours (UZ); 2011, Certificate: Module Writing; 2011, Certificate: Managing the training programme - ESAMI, Tanzania; 1990, Certificate advanced work study (Canada); 1986, Certificate: Organisation and methods $\mathrm{O} \& \mathrm{M}$ ), Institute of Development Administration IDM Botswana); 1983, Certificate in Labour Administration, African Regional Labour Administration Centre (ARLAC) (Nairobi); 1964, Primary Teachers Higher Certificate (PHT) Waddilove Teacher Training Institution, Marondera, Zimbabwe 